\title{
Evaluation and comparison of skeletal and dental maturity indicators in individuals with different growth pattern
}

\author{
Dr R.H.Kamble ${ }^{1}$, Dr Pritesh Singla ${ }^{2}$, Dr Jayant Wankhede ${ }^{3}$, Dr PallavKumar \\ Ghoshal $^{4}$, Dr Jeet Singh ${ }^{5}$ \\ 1(Professor, Department of Orthodontics, SharadPawar dental College, DattaMeghe Institute of Medical \\ Sciences, India) \\ 2(Reader, Department of Orthodontics, Adesh institute of Dental Sciences \& Research,Adesh University, India) \\ 3(Lecturer, Department of Orthodontics, SharadPawar dental College, DattaMeghe Institute of Medical \\ Sciences, India) \\ 4(Post graduate student, Department of Orthodontics, SharadPawar dental College, DattaMeghe Institute of \\ Medical Sciences, India) \\ 5(Post graduate student, Department of Orthodontics, SharadPawar dental College, DattaMeghe Institute of \\ Medical Sciences, India)
}

\begin{abstract}
Introduction- Assessment of maturational status is a decisive factor in deciding treatment modality. Various methods till date have been tested to define individual's maturation. This study comprised of 60 samples divided in 3 groups. Group I normal grower (control), group II - vertical growers and group III - horizontal growers. Each sample was assessed for skeletal and dental age using CVMI, SMI stages and canine calcification stages respectively. All data in the groups was analyzed by Annova test. Subgroup data and comparisons were analyzed by Dunnett D test and t-test. Results showed that dental maturation was delayed in horizontal growers as compared to vertical growers with $p$-value of 0.00 and 0.044 . There was non-significant difference in dental maturation of male and females with p-value >0.05. Comparison of skeletal maturation by hand wrist radiograph showed significant variation in group III with delayed skeletal maturation of horizontal growers than control group with p-value $<0.05$. Dunnett D test showed main skeletal age by CVMI was significant with p-value of 0.00 which indicates that skeletal age of group III to be lower in all groups. Rest was non-significant.
\end{abstract}

Keywords: Chronological age, CVMI, Dental age, Skeletal age, SMI.

\section{Introduction}

Assessment of maturational status is a decisive factor in diagnosis, treatment planning and the eventual outcome of orthodontic treatment. Assessing maturational status is more important when the clinical considerations are based strongly on the increased or decreased rates of craniofacial growth left, such as the timing and use of extra oral traction and the use of functional appliances. Also it helps in predicting future growth potential of the facial skeleton in order to ensure successful outcome of the treatment of dentofacial deformities. ${ }^{[1]}$

Racial \& sexual differences and other less tangible factors such as climate, nutrition, socio-economic levels \& urbanization may influence the rates of physiologic maturity of a child. This renders the chronological age as unreliable indicator of maturational levels. ${ }^{[2]}$ The hand wrist radiograph is commonly used for the assessment of skeletal development as many investigators have found significant correlation between maturation stages. ${ }^{[2][3][4][5][6]}$ Also changing concavities in the lower border of cervical vertebrae are also found to be a reliable method for assessing skeletal development apart from hand wrist. ${ }^{[7][8][9][10][11][12]}$

Sandra Coutinhoet al (1993) ${ }^{[13]}$ found a close relationship between the canine calcification stage G in the mandible with the pubertal growth spurt. However it remain questionable whether association based on dental stages are strong enough to make reliable clinical predictions. The difference in dental maturation between skeletal open bite and skeletal deep bite subjects was investigated by Janson et al (1998) ${ }^{[14]}$ and reported that skeletal open bite subjects presented a slight tendency to have an advanced dental maturation expressed by the dental age.

Janson $(1998)^{[14]}$, Nanda and Rowe (1989) ${ }^{[15]}$ also concluded that timings of the adolescent growth spurt for various facial dimensions in open bite faces were earlier than deep bite faces. Also studies conducted by different investigators to assess the correlation between different facial types i.e. skeletal open bite \& skeletal deep bite on dental maturation have shown that there is a difference in the timings of dental maturation between these extreme vertical facial types. ${ }^{[16]}$ 
The timing of craniofacial growth and its relationship to other developmental events presents a particular challenge in subjects exhibiting variations in facial form. Considering the lack of data on variability of skeletal maturation between the two facial types, present study was carried out to establish whether the vertical and horizontal growth patterns influence the rate of dental \& skeletal maturation as compared to normal growth patterns. Also the study probed any sexual dimorphism on the rate of dental and skeletal maturation between the vertical and the horizontal growers.

\section{Methods}

The study consisted of 60 individuals of chronological ages between 8-14 yrs. Selection criteria includes individuals with no history of bony deformities and pathosis, no muscular dystrophy, congenital abnormalities, traumatic injuries to the jaws and hands. Approval from ethical committee of DattaMeghe Institute of Medical Sciences Deemed University was taken prior to the study.

Lateral cephalogram, OPG (PlanmecaProline and Vision 100A) and hand wrist radiographs were taken for each sample. Mandibular plane angle was used to divide the samples into three groups i.e. Group I (normal growers- control group), Group II (vertical growers) and group III (horizontal growers). Group II and Group III were further subdivided into two subgroups as subgroup A (males) and B (females).

All the samples were evaluated for their respective stages of skeletal and dental maturation as per the methods developed by Fishman for SMI stages using handwrist radiographs, for CVMI stages using lateral cephalogram (Hassel and F arman) ${ }^{[8]}$. Demirijian $(1973)^{[17]}$ index was used to assess dental age using OPG.

\section{Results}

The mean chronological age for Group I, II and III was 10.90 $\pm 0.47,10.14 \pm 0.98$ and 10.24 \pm 1.45 respectively.

Table no.1: Mean dental age (years) in three groups (descriptive statistics)

\begin{tabular}{|c|c|c|c|c|c|c|c|c|}
\hline \multirow[t]{2}{*}{ Group } & \multirow[t]{2}{*}{$\mathrm{n}$} & \multirow[t]{2}{*}{ Mean } & \multirow[t]{2}{*}{ Standard deviation } & \multirow{2}{*}{$\begin{array}{l}\text { Standard } \\
\text { error }\end{array}$} & \multicolumn{2}{|c|}{$95 \%$ of confidence } & \multirow[t]{2}{*}{ Min. } & \multirow[t]{2}{*}{ Max. } \\
\hline & & & & & Lower bound & Upper bound & & \\
\hline Gr. III & 20 & 9.66 & 1.46 & 0.32 & 8.97 & 10.35 & 7.30 & 12.40 \\
\hline Gr. II & 20 & 10.67 & 1.02 & 0.23 & 10.18 & 11.15 & 7.90 & 12.40 \\
\hline Gr. I & 20 & 11.49 & 0.74 & 0.16 & 11.14 & 11.84 & 10.00 & 12.50 \\
\hline
\end{tabular}

Table no.2-Mean dental age (Multiple comparison Dunnett D test)

\begin{tabular}{|l|l|l|l|l|l|l|}
\hline \multirow{2}{*}{ Group } & \multirow{2}{*}{$\begin{array}{l}\text { Mean Difference } \\
(\mathrm{I}-\mathrm{J})\end{array}$} & \multirow{2}{*}{ Std. Error } & \multirow{2}{*}{ p-value } & \multicolumn{2}{|c|}{$95 \%$ confidence Interval } \\
\cline { 5 - 7 } & \multirow{2}{*}{ Gr. III } & -1.86 & 0.35 & $0.000 \mathrm{~S} \mathrm{p}<0.05$ & -2.63 & -1.02 \\
\cline { 5 - 7 } & Gr. II & -0.82 & 0.35 & $0.044 \mathrm{~S}$ P $<0.05$ & -1.63 & -0.01 \\
\hline
\end{tabular}

Table no.3-Results of Independent t-test between dental ages of vertical (Gr. II) and horizontal group (Gr. III)

\begin{tabular}{|l|l|l|l|l|l|l|}
\hline \multirow{2}{*}{ Variable } & \multicolumn{2}{|c|}{ Gr. II } & Gr. III & \multirow{2}{*}{ Difference } & \multirow{2}{*}{ p-value } \\
\cline { 2 - 7 } & Mean & SD & Mean & SD & & \\
\hline Dental Age & 10.67 & 1.04 & 9.66 & 1.46 & -1.00 & $0.01 \mathrm{~S} \mathrm{p}<0.05$ \\
\hline
\end{tabular}

Table no.4-Results of independent t-test in horizontal and vertical subgroups (male and female)

\begin{tabular}{|l|l|l|l|l|l|l|}
\hline \multirow{2}{*}{ Group } & Subgroup A & \multicolumn{2}{|c|}{ Subgroup B } & \multirow{2}{*}{ Difference } & \multirow{2}{*}{ p-value } \\
\cline { 2 - 6 } \multicolumn{1}{c}{ Gr. III } & Mean & SD & Mean & SD & 0.45 & 0.50 NS p $>0.05$ \\
\hline Gr. II & 10.08 & 0.76 & 9.44 & 1.96 & 0.45 & $0.01 \mathrm{~S} \mathrm{P}<0.05$ \\
\hline
\end{tabular}

Table no.5-Multiple comparison within groups: Dunnett D test (SMI with hand wrist)

\begin{tabular}{|c|c|c|c|c|c|c|}
\hline \multirow{2}{*}{\multicolumn{2}{|c|}{ Group }} & \multirow{2}{*}{$\begin{array}{c}\text { Mean } \\
\text { Difference (I-J) }\end{array}$} & \multirow{2}{*}{ Std. Error } & \multirow{2}{*}{ p-value } & \multicolumn{2}{|c|}{$95 \%$ confidence Interval } \\
\hline & & & & & & \\
\hline Gr. III & \multirow{2}{*}{ Gr. I } & -0.99 & 0.28 & $\begin{array}{l}0.002 \mathrm{~S} \\
\mathrm{p}<0.05\end{array}$ & -1.62 & -0.35 \\
\hline Gr. II & & -0.45 & 0.28 & $\begin{array}{l}0.20 \mathrm{NS} \\
p>0.05\end{array}$ & -1.08 & 0.18 \\
\hline
\end{tabular}

Table no.6-Results of Independent t-test between skeletal ages of Gr.II \& Gr.III using SMI

\begin{tabular}{|l|l|l|l|l|l|l|}
\hline \multirow{2}{*}{ Variable } & Gr.II & Gr.III & \multirow{2}{*}{ Difference } & \multirow{2}{*}{ p-value } \\
\cline { 2 - 5 } & Mean & SD & Mean & SD & & \\
\hline Skeletal Age & 11.64 & 1.03 & 11.10 & 0.88 & -0.54 & $0.08 \mathrm{NS} \mathrm{p}>0.05$ \\
\hline
\end{tabular}


Evaluation and comparison of skeletal and dental maturity indicators in individuals with....

Table no.7-Results of independent t-test for skeletal age between subgroups (using SMI)

\begin{tabular}{|l|l|l|l|l|l|l|}
\hline \multirow{2}{*}{ Group } & Subgroup A & Subgroup B & Difference & p-value \\
\cline { 2 - 7 } & Mean & SD & Mean & SD & \\
\hline Gr. III & 11.24 & 0.50 & 10.97 & 1.16 & 0.27 & $0.50 \mathrm{NS} \mathrm{p}>0.05$ \\
\hline Gr. II & 12.10 & 1.11 & 11.19 & 0.75 & 0.91 & $0.04 \mathrm{~S}$ P $<0.05$ \\
\hline
\end{tabular}

Table no.8-Multiple comparison within group: Dunnett D test(CVMI)

\begin{tabular}{|c|c|c|c|c|c|c|}
\hline \multirow{2}{*}{\multicolumn{2}{|c|}{ Group }} & \multirow{3}{*}{$\begin{array}{l}\text { Mean } \\
\text { Difference (I-J) } \\
-1.41\end{array}$} & \multirow{3}{*}{$\begin{array}{l}\text { Std. Error } \\
0.30 \\
\end{array}$} & \multirow{3}{*}{$\begin{array}{l}\text {-value } \\
0.000 \mathrm{~S} \mathrm{p}<0.05 \\
\end{array}$} & \multirow{2}{*}{\multicolumn{2}{|c|}{$95 \%$ confidence Interval }} \\
\hline & & & & & & \\
\hline Gr. III & \multirow[b]{2}{*}{ Gr. I } & & & & -2.10 & -0.72 \\
\hline Gr. II & & -1.00 & 0.30 & $0.003 \mathrm{~S} \mathrm{P}<0.05$ & -1.68 & -0.31 \\
\hline
\end{tabular}

Table no.9- Results of independent t- test between skeletal ages (CVMI) of Vertical and Horizontal Group

\begin{tabular}{|l|l|l|l|l|l|l|}
\hline Variable & Gr. II & Gr. III & Difference & p-value \\
\cline { 2 - 5 } & Mean & SD & Mean & SD & & \\
\hline Skeletal Age & 10.60 & 0.98 & 10.19 & 0.98 & -0.41 & $0.19 \mathrm{NS} \mathrm{p}>0.05$ \\
\hline
\end{tabular}

Table no.10- Results of independent t-test between skeletal agebetween subgroups (using CVMI).

\begin{tabular}{|l|l|l|l|l|l|l|}
\hline \multirow{2}{*}{ Group } & \multicolumn{4}{|l|}{ Subgroup A } & \multicolumn{3}{|l|}{ Subgroup B } & \multirow{2}{*}{ Difference } & \multirow{2}{*}{ p-value } \\
\cline { 2 - 5 } & Mean & SD & Mean & SD & -0.84 & 0.05 NS p $>0.05$ \\
\hline Gr. III & 9.77 & 0.71 & 10.61 & 1.07 & -0.84 & $0.39 \mathrm{NSp}>0.05$ \\
\hline Gr. II & 10.41 & 1.15 & 10.80 & 0.78 & -0.39 & 0 \\
\hline
\end{tabular}

\section{Discussion}

Comparison of dental maturation in all three groups (Demirjian stages)

The mean dental age for Group I, II and III was $11.49 \pm 0.74,10.67 \pm 1.04$ and $9.66 \pm 1.46$ respectively.[Table no.1][Graph no.1].

Analysis of variance (One way Anova test) showed that there exists statistically significant variation in all the three types of growth patterns with p- value $<0.05(0.00)$.

Multiple comparison Dunnet D test showed that mean dental age of group III was lowest followed by group II as compared with $\mathrm{p}$ value of 0.00 and 0.044 respectively.[Table no.2] ][Graph no.1].

Independent t-test showed statistically significant variation with p-value of 0.01 , suggestive of delayed dental maturation in horizontal growers when compared to vertical growers. [Table no.3].

The present study showed results which are comparable to those of Neves et al (2005) ${ }^{[16]}$ showing early maturation and a more advanced dental age for the vertical growers with the mean difference of 1.00 as compared to horizontal growers. Also Janson et al (1998) ${ }^{[14]}$ studied the differences in dental maturation between skeletal open and deep bite subjects in 40 subjects with mean of 9.2 years and reported that skeletal open bite subjects have advanced dental maturation, expressed by dental age, as compared to skeletal deep bite subjects.

Dental maturation in subgroups was found to be significant with p- value $>0.05(0.01)$ suggestive of female vertical growers to be ahead in growth spurt as compared to male vertical growers. However present study showed no significant difference in dental maturation in female horizontal growers. [Table no.4]. This is comparable with the results ofNanda (1988) ${ }^{[\mathbf{1 8 ]}}$ who conducted a study on 16 males and 16 females and reported that female open bite subjects were earlier in timing of adolescent growth spurt than the male open bite subjects. Comparison of skeletal maturation in all three groups:

(A) SMI stages using hand wrist radiographs:

The mean skeletal age for Group I, II, and III was $12.09 \pm 0.72,11.64 \pm 1.03$ and $11.10 \pm 0.88$, respectively. Multiple comparison Dunnet D Test showed that Group III was statistically significant with p- value $<0.05$ when the groups were compared. It suggests that horizontal growers when compared to normal growers showed delayed skeletal maturation whereas no significant variation in skeletal maturation was seen when vertical growers were compared to normal growers.[Table no.5]

Independent t-test showed that the skeletal age is ahead in Group II as compared to Group III but with statistically non-significant.(p>1.77) [Table no.6].Suggestive of non-significant variation in skeletal maturation when horizontal growers were compared to vertical growers.

Significant difference between males and females was found in subgroup II with p-value $<0.05(0.04)$ suggestive of male vertical growers being ahead of skeletal maturation when compared to female vertical growers.[Table no.7]

(B) Comparison of Skeletal maturation using CVMI:

Multiple comparison Dunnet D test showed mean skeletal age of group III to be lowest followed by group II and was statistically significant with $\mathrm{p}$ value of 0.00 and 0.003 respectively when compared with group I.[ Table no.8] 
Evaluation and comparison of skeletal and dental maturity indicators in individuals with....

Also no significant variations in skeletal maturation was observed when horizontal growers were compared to vertical growers.[ Table no.9 and 10]

Graph 1: Mean ages of three groups

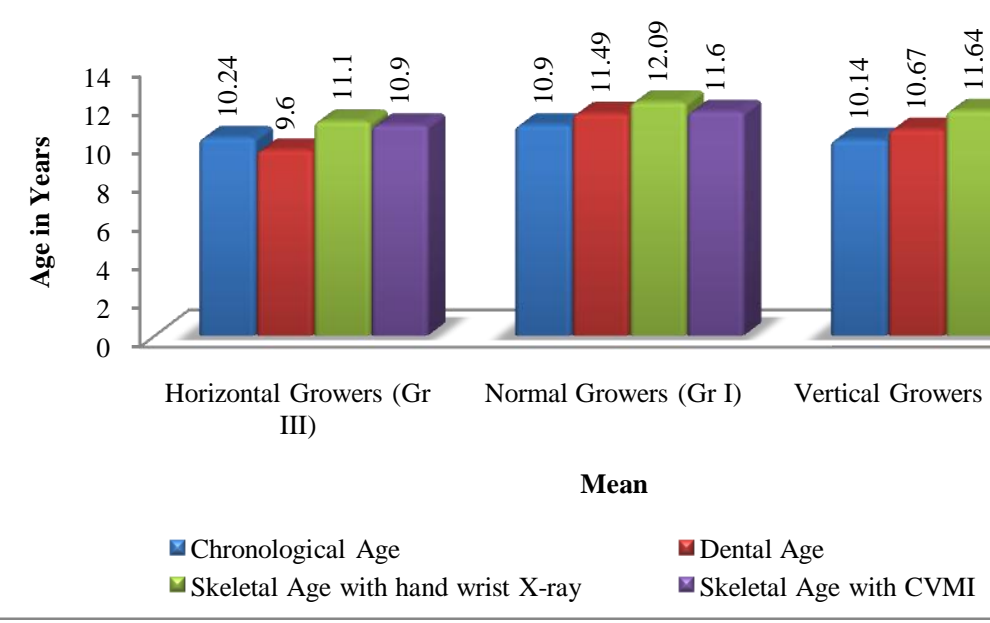

Graph 2: Comparison of two Subgroups

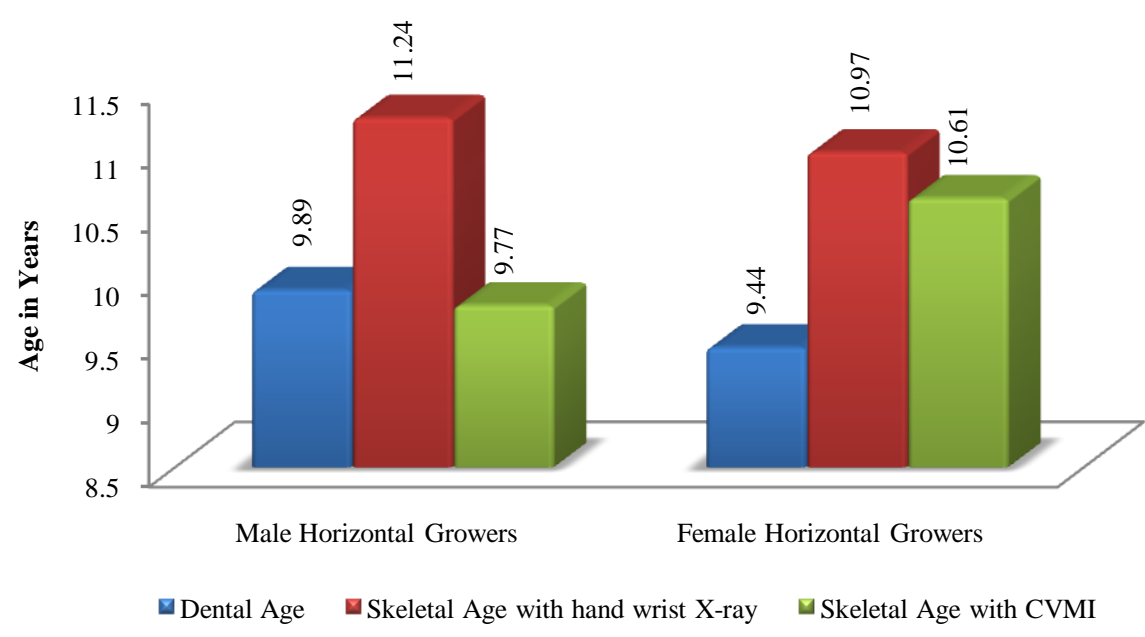

Graph 3: Comparison of two Subgroups

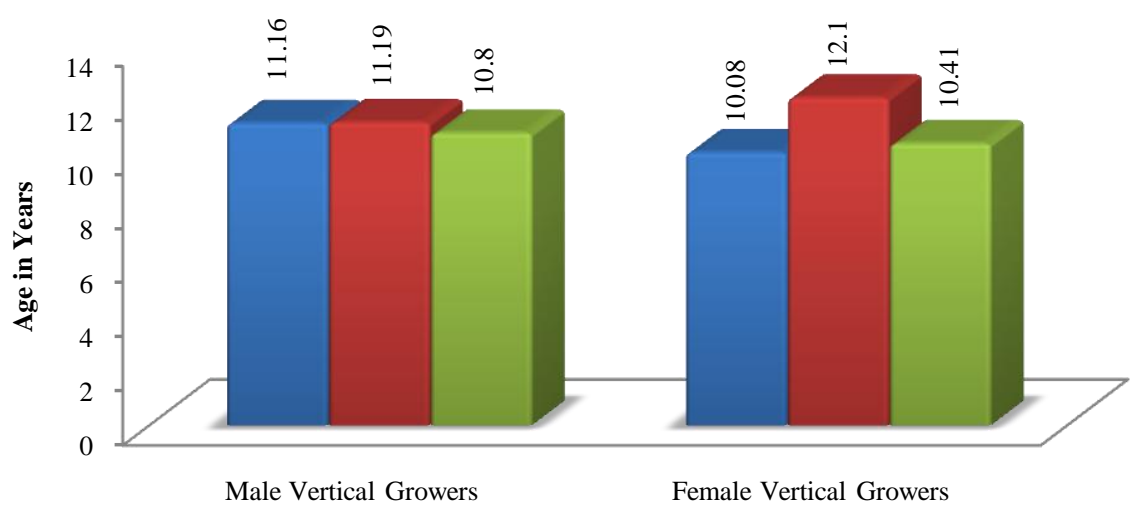

$\square$ Dental Age $\square$ Skeletal Age with hand wrist X-ray $\square$ Skeletal Age with CVMI 
Following conclusions were drawn:

\section{Conclusion}

1) Dental maturation in vertical and horizontal growing individuals using OPG:

- Individuals with horizontal growth pattern showed delayed dental maturation when compared to vertical growers.

- Female vertical growers are ahead of males in dental maturation.

2) Skeletal maturation in vertical and horizontal growing individuals using SMI and CVMI :

- Although it was found that horizontal growth pattern individuals showed a delay in skeletal maturation when compared to vertical growers but the difference was not statistically significant.

- Female vertical growers have advanced skeletal maturation than male vertical growers.

3) Skeletal maturation in vertical and horizontal growing individuals using CVMI in lateral cephalogram:

- Although female vertical and horizontal growers have advanced skeletal maturation but the difference was not statistically significant.

\section{References}

[1]. S. Chertkow, Tooth mineralization as an indicator of the pubertal growth spurt, Am J OrthodDentofacialOrthop,49,1980,282-288

[2]. L.S Fishman,Chronological versus skeletal age, an evaluation of craniofacial growth, Angle Orthod,49, 1979, $181-189$.

[3]. L.S Fishman,Maturational Patterns and Prediction during Adolescence, Angle Orthod, 57, 1987, 178-193.

[4]. F.E Johnston,Skeletal maturation and cephalofacial development, Angle Orthod, 35, 1965, 1-11.

[5]. Alex F Roche,The reliability of assessments of the maturity of individual hand-wrist bones, Human Biol,48, 1976,585-597.

[6]. L.S Fishman,Radiographic evaluation of skeletal maturation,Angle Orthod, 52, 1982, 88-112.

[7]. D Lamparski,Skeletal age assessment utilizing cervical vertebrae, Am J OrthodDentofacialOrthop, 107,1995,58-66.

[8]. B. Hassel, Allan G Farman,Skeletal maturation evaluation using cervical vertebrae, Am J OrthodDentofacialOrthop, 107, 1995, 5866.

[9]. LJ Green,The interrelationship among height, weight and chronological,dental and skeletal ages,Angle Orthod,31, 1961,189-193.

[10]. Fernandez P Garcia,The cervical vertebrae as maturation indicator, J. ClinOrthod, 35, 1998,221-225.

[11]. K.SNegi, Assessment of growth Impetus using MP3 maturation and its correlation with CVMI and dental age,J IndOrthodSoc36, 2003, 204-213.

[12]. NDabla, A Comparative Evaluation of Modified MP3 and CVMI Stages As Maturation Indicators,J IndOrthodSoc, 39, 2006,147154.

[13]. SandraCoutinho, Relationship between mandibular canine calcification stages and skeletal maturity, Am J OrthodDentofacialOrthop, $104,1993,262-268$.

[14]. JansonGuilherme, Dental maturation in subjects with extreme facial patterns,Eur J Orthod, 20, 1998,73-78.

[15]. SK Nanda, T K Rowe,Circumpubertal growth spurt related to vertical dysplasia, Angle Orthod, 59, 1989, $113-122$.

[16]. L.SantosNeves,Comparative study of the maturation of permanent teeth in subjects with vertical and horizontal growth patterns, Am J OrthodDentofacial Orthop,128, 2005, 619-23.

[17]. ADemirjian,A new system of dental age assessment, Human Biol, 45, 1973, 211-227.

[18]. S.KNanda,Patterns of vertical growth in the face,Am J OrthodDentofacialOrthop, 93, 1988,103-16. 